also inserted a left intercostal chest drain. Routine postrepair chest radiograph is advised. In our practice, we recommend the routine use of a sternal support for the following 3 months. We believe that correction with Flexigrips is a safer and simpler way of dealing with post-cardiac surgery sternal instability and should be used more frequently.

\section{References}

1. Centofanti P, La Torre M, Barbato L, Verzini A, Patane F, di Summa M. Sterna closure using semirigid fixation with thermoreactive clips. Ann Thorac Surg. 2002;74:943-5.

2. Negri A, Manfredi J, Terrini A, Rodella G, Bisleri G, El Quarra S, Muneretto C Prospective evaluation of a new sternal closure method with thermoreactive clips. Eur J Cardiothoracic Surg. 2002;22:571-5.

\title{
A novel solution for repeated migration of an implantable cardiac defibrillator
}

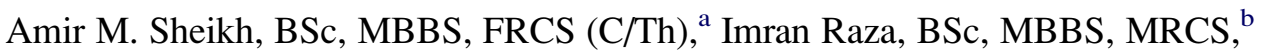 \\ Simon Charles Edwin Sporton, BSc, MBBS, MD, MRCP, ${ }^{\mathrm{c}}$ and Kulvinder S. Lall, MBBS, FRCS, ${ }^{\mathrm{d}}$ Toronto, \\ Ontario, Canada, and Kent and London, United Kingdom
}

Migration and extrusion of pacemakers and implantable cardiac defibrillators (ICDs) has been reduced over the years as devices have become smaller and lighter. However, this phenomenon still occurs. We present a case in which this problem occurred repeatedly, leading to a novel easily fashioned solution for this previously more common problem.

\section{CLINICAL SUMMARY}

A 69-year-old man was referred to the cardiothoracic surgeons for help with repositioning of a migrating ICD in 2007. A dual-chamber ICD was originally inserted in 2004 for sustained ventricular tachycardia. The pulse generator was placed in a subpectoral pocket. The pulse generator subsequently migrated laterally and was repositioned in 2005 to a more medial subpectoral pocket. The patient returned with pain and threatened erosion to the inferior part of the male breast fold. The patient's recurrent problem had a number of predisposing factors. He was overweight at $89 \mathrm{~kg}$ and had signs of gynecomastia owing to spironolactone therapy. He had a history of chronic obstructive airway disease with

\footnotetext{
From the Division of Cardiac Surgery, ${ }^{\text {a }}$ Toronto General Hospital, Toronto, Ontario,

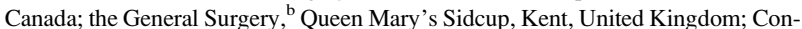
sultant in of Cardiology ${ }^{\mathrm{c}}$ and Cardiothoracic Surgery, ${ }^{\mathrm{d}}$ Barts and The London NHS Trust, London, United Kingdom.

At the time of this report, Dr Raza's affiliation was Cardiothoracic Senior House Officer, St Bartholomew's Hospital, Department of Cardiothoracic Surgery, West Smithfield, London, United Kingdom.

Disclosures: None.

Received for publication Oct 4, 2008; revisions received Nov 25, 2008; accepted for publication Dec 19, 2008; available ahead of print March 9, 2009.

Address for reprints: Imran Raza, BSc, MBBS, MRCS, Queen Mary's Sidcup, Frognal Ave, Sidcup, Kent, DA14 6LT, United Kingdom (E-mail: imrani@yahoo.com). J Thorac Cardiovasc Surg 2010;139:499-501

$0022-5223 / \$ 36.00$

Copyright (c) 2010 by The American Association for Thoracic Surgery doi:10.1016/j.jtcvs.2008.12.015
}

home oxygen therapy and inhaled steroid medication, with multiple enteral steroid courses. He also had a history of ischemic heart disease for which he had undergone a coronary artery bypass graft many years previously.

There was no evidence of twiddler's syndrome, as has been described in many previous case reports of ICD migration or failure requiring repositioning. ${ }^{1-3}$ The ICD itself was still functional and there was no evidence of lead dislodgment, fracture, or malfunction from chest radiographs and from ICD interrogation.

With the patient under general anesthesia, the ICD was approached via the left deltopectoral scar from previous insertions. The generator and leads were easily located and dissected free. The generator was detached and the leads were checked and found to be functioning normally. The opportunity was taken to insert a new generator.

Prolene mesh (Ethicon, Inc, Somerville, NJ) and 2-0 polypropylene sutures were used to fashion a pouch around the ICD. The mesh was folded around the ICD and the two open edges were sutured with a horizontal running mattress suture, followed by a continuous over-and-over suture (Figures 1 and 2). The mesh was ensured to be tight around the lead-box connections (Figure 3). The pouch and the enclosed ICD were returned to the subpectoral space, ensuring the sutured edges of the pouch were facing superiorly. With multiple interrupted 2-0 polypropylene sutures applied to the edge of the pouch, the pouch was sutured to the underlying subpectoral fascia. The overlying pectus muscle was closed with interrupted $2-0$ absorbable braided suture, and the remaining layers were closed in routine fashion.

The patient was discharged home without complication and on last consultation, approximately 6 months after the procedure, was well and described no problems with the ICD. Specifically, there were no problems with ICD displacement or discomfort. 

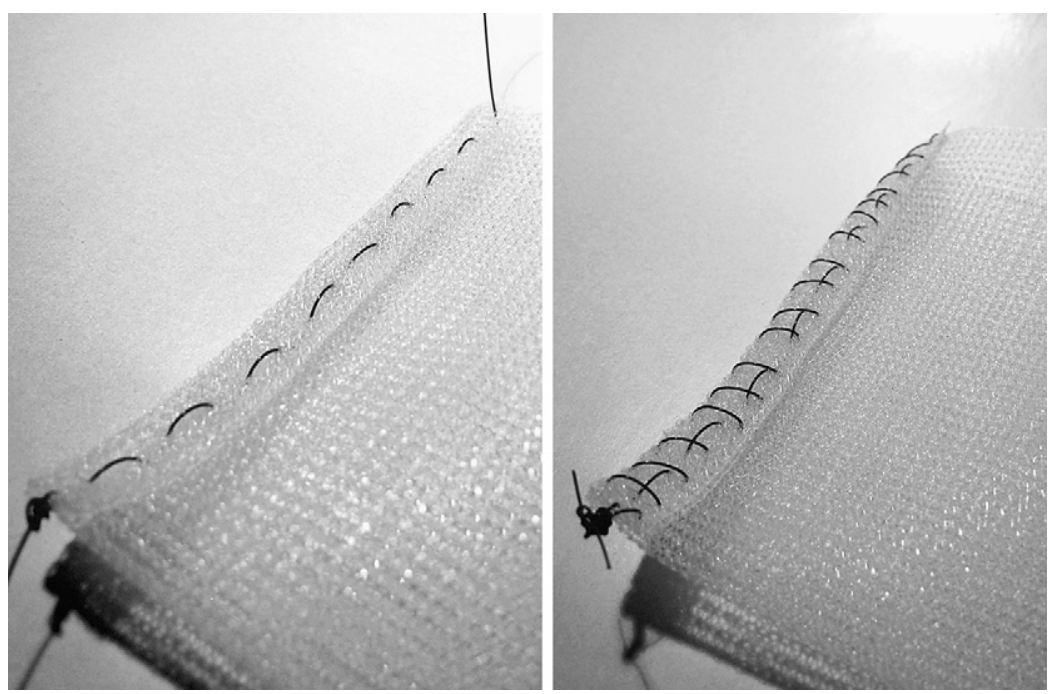

FIGURE 1. The side borders are stitched first to create a pocket from the polypropylene mesh. The left border is shown here. By folding the edge, we fashioned a hem using a double layer of polypropylene suture, first a continuous running mattress, followed by a continuous over-and-over suture.

\section{DISCUSSION}

The Parsonnet Pouch (Bard, Peripheral Vascular Division, Tempe, Ariz) has long been known about and described in the literature as a method of securing ICDs and pacemakers from migrating and extruding. ${ }^{4}$ With advancement in this field, pacemakers and ICDs in particular have been reduced vastly in size and weight. In the series by Par-

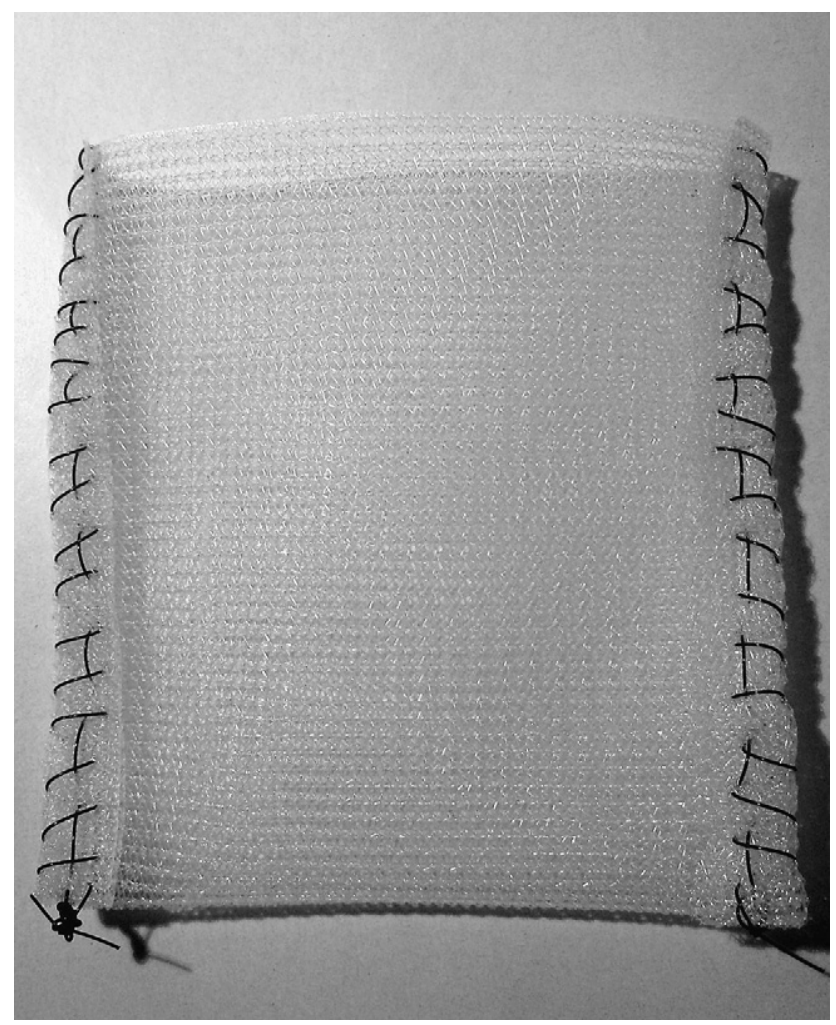

FIGURE 2. Both sides have been completed, making the pocket.

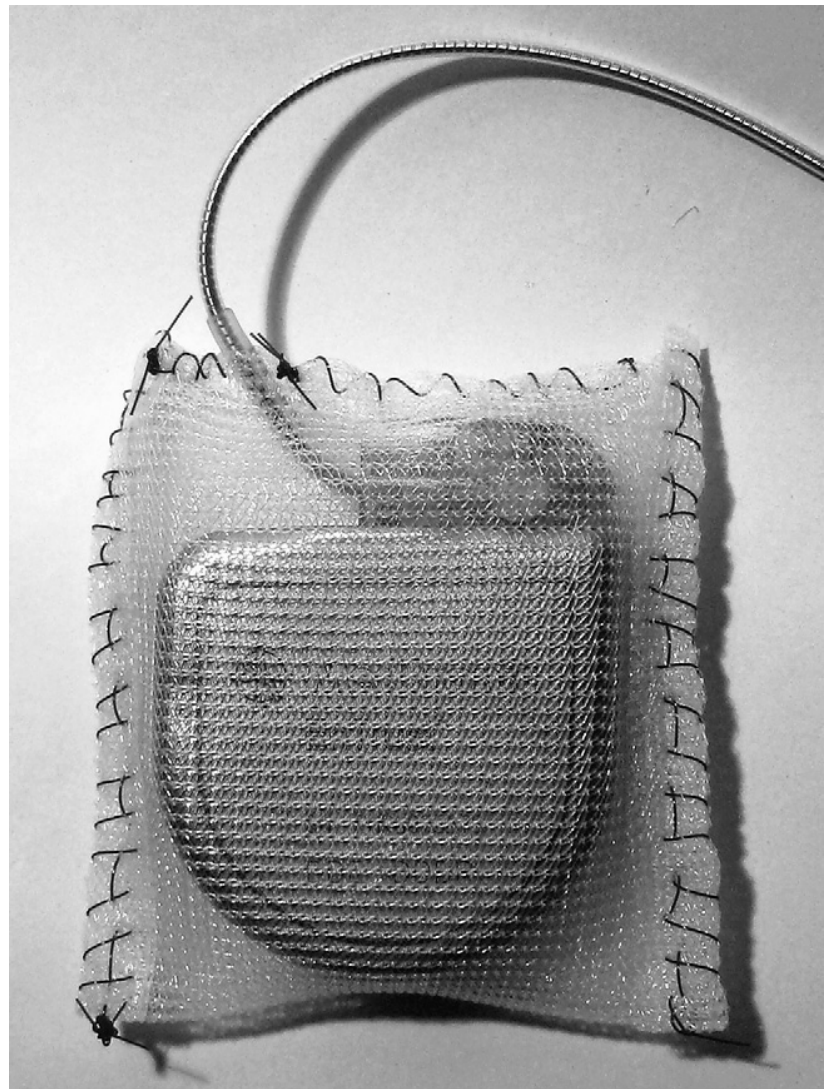

FIGURE 3. The completed product. The ICD has been inserted into the pocket and the upper edge sewn closed, just allowing the leads to exit. The ICD pocket is inserted and orientated in the patient so that the inferior edge (ie, the folded, nonsewn edge, as shown) will lie inferiorly when the patient is in a standing position. 
sonnet and associates, ${ }^{4}$ of the three types of ICDs used, all weighed $240 \mathrm{~g}$ or more. This is much heavier than the ICDs of today. In fact, the lightest pacemaker (not ICD) they describe is about the average weight of today's ICDs. This in itself has reduced the amount of migration and extrusion seen over the years. Although previously advocated for use in all implants of ICDs, the use of the Parsonnet pouch has dwindled for the aforementioned reason, except in rare cases. $^{5}$

The case described here is one of these rarities and has shown that extrusions can still occur in certain circumstances, even with new devices.

The availability of the Parsonnet pouch along with the cost means that these pouches are not kept routinely, even at major institutions or tertiary referral centers. Prolene mesh is readily available, particularly given its use in inguinal hernia repairs. In the procedure described herein, we fashioned a pouch out of a readily available material. This was an easier and cheaper solution than a specialist product. The described technique could also be applied to repeated migration of a pacemaker.

\section{References}

1. Bracke F, van Gelder B, Dijkman B, Meijer A. Lead system causing twiddler's syndrome in patients with an implantable cardioverter-defibrillator. J Thorac Cardiovasc Surg. 2005;129:231-2.

2. Bhatia V, Kachru R, Parida A, Kaul U. Twiddlers syndrome. Int J Cardiol. 2007; 116:e82.

3. Higgins SL, Suh BD, Stein JB, Meyer DB, Jons J, Willis D. Recurrent Twiddler's syndrome in a nonthoracotomy ICD system despite a Dacron pouch. Pacing Clin Electrophysiol. 1998;21(1 Pt 1):130-3.

4. Parsonnet V, Bernstein AD, Neglia D, Omar A. The usefulness of a stretch-polyester pouch to encase implanted pacemakers and defibrillators. Pacing Clin Electrophysiol. 1994;17(12 Pt 1):2274-8.

5. Parsonnet V, Shapiro J. Unique Dacron reaction to an implanted pulse generator Pacing Clin Electrophysiol. 2005;8:864-6.

\section{Heart transplantation in situs inversus totalis}

Tobias Deuse, MD, and Bruce A. Reitz, MD, Stanford, Calif

Heart transplantation for situs inversus totalis is surgically challenging because it requires reconstruction of the mirror-image systemic venous pathways.

\footnotetext{
From the Department of Cardiothoracic Surgery, Stanford University School of Medicine, Stanford, Calif.

Disclosures: None.

Received for publication Dec 9, 2008; accepted for publication Dec 19, 2008; available ahead of print Feb 9, 2009.

Address for reprints: Tobias Deuse, MD, Department of Cardiothoracic Surgery, Stanford University School of Medicine, 300 Pasteur Dr, CVRB MC 5407, Stanford,

CA 94305 (E-mail: deuse@stanford.edu).

J Thorac Cardiovasc Surg 2010;139:501-3

$0022-5223 / \$ 36.00$

Copyright (c) 2010 by The American Association for Thoracic Surgery doi:10.1016/j.jtcvs.2008.12.011
}

\section{CLINICAL SUMMARY}

The patient presented is a 6-year-old boy in heart failure, weighing $17 \mathrm{~kg}$, with situs inversus, dextrocardia, unbalanced atrioventricular canal, double-outlet right ventricle, mitral and pulmonary atresia, and bilateral superior vena cavae (SVCs). He had previous Blalock-Taussig and bidirectional Glenn shunts placed (Figure 1, A). Heart transplantation was performed as described in Figure 2, using a normal donor heart. The postoperative chest radiograph demonstrated dextrocardia of the transplanted heart (Figure 1,B).

\section{DISCUSSION}

The left atrium is a midline structure; the pulmonary artery, if developed, crosses the midline at some point; and

\section{pre transplant}

\section{post transplant}
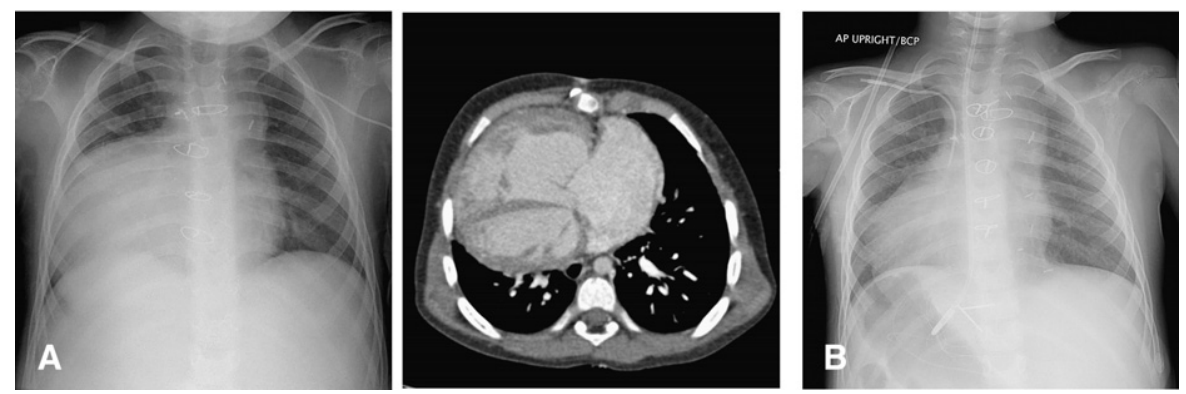

FIGURE 1. A, Pretransplantation imaging studies reveal situs inversus and dextrocardia. B, After heart transplantation, the normal donor heart remains in dextrocardia. 